\title{
The Anti-Inflammatory and Anti-Oxidant Mechanisms of the Keap1/Nrf2/ARE Signaling Pathway in Chronic Diseases
}

\author{
Wenjun Tu' ${ }^{1,2,3, \#, ~ H o n g ~ W a n g 4, \#, ~ S o n g ~ L i ~}{ }^{1}$, Qiang Liu ${ }^{1, *}$, Hong Sha ${ }^{4, *}$ \\ ${ }^{1}$ Institute of Radiation Medicine, China Academy of Medical Science \& Peking Union Medical College, Tianjin, \\ China \\ ${ }^{2}$ Department of Neurosurgery, Beijing Tiantan Hospital of Capital Medical University, Beijing, China \\ ${ }^{3}$ Center for Translational Medicine, Institutes of Stroke, Weifang Medical University, Weifang, China \\ ${ }^{4}$ Institute of Biomedical Engineering, China Academy of Medical Science \& Peking Union Medical College, \\ Tianjin, China
}

[Received April 2, 2018; Revised May 10, 2018; Accepted May 12, 2018]

\begin{abstract}
Oxidative stress is defined as an imbalance between production of free radicals and reactive metabolites or [reactive oxygen species (ROS)] and their elimination by through protective mechanisms, including (antioxidants). This Such imbalance leads to damage of cells and important biomolecules and cells, with hence posing a potential adverse impact on the whole organism. At the center of the day-to-day biological response to oxidative stress is the Kelch-like ECH-associated protein 1 (Keap1) - nuclear factor erythroid 2-related factor 2 (Nrf2)- antioxidant response elements (ARE) pathway, which regulates the transcription of many several antioxidant genes that preserve cellular homeostasis and detoxification genes that process and eliminate carcinogens and toxins before they can cause damage. The redox-sensitive signaling system Keap1/Nrf2/ARE plays a key role in the maintenance of cellular homeostasis under stress, inflammatory, carcinogenic, and pro-apoptotic conditions, which allows us to consider it as a pharmacological target. Herein, we review and discuss the recent advancements in the regulation of the Keap1/Nrf2/ARE system, and its role under physiological and pathophysiological conditions, e.g. such as in exercise, diabetes, cardiovascular diseases, cancer, neurodegenerative disorders, stroke, liver and kidney system, etc. and such.
\end{abstract}

Key words: Oxidative stress, Reactive oxygen species, Keap1/Nrf2/ARE, Anti-inflammatory, Anti-oxidant, Lowlevel laser irradiation

\section{Oxidative stress}

Oxidative stress, as a concept in redox biology and medicine, has been formulated in 1985 [1]. In the beginning of 2018, approximately 188 188,737 PubMed entries are show for displayed for this term. Oxidative stress is defined as an imbalance between the production of free radicals and reactive metabolites or [reactive oxygen species (ROS)] and their elimination by through protective mechanisms such as (antioxidants) [2]. This imbalance leads to damage of cells and important vital biomolecules and cells, with potential impact on the whole organism [3].

ROS, which are products of a normal cellular metabolism and, play vital roles in the stimulation of signaling pathways in plant and animal cells in response to changes in intra- and extra-cellular environmental conditions [4]. Most ROS are generated by the

*Correspondence should be addressed to: Dr. Qiang Liu (Email: liuqiang_cams@163.com) or Dr. Hong Sha (Email: shahong2000@ 163.com), China Academy of Medical Science \& Peking Union Medical College, Tianjin, China. "These authors contributed equally to this study.

Copyright: () $2018 \mathrm{Tu} \mathrm{W}$ et al. This is an open-access article distributed under the terms of the Creative Commons Attribution License, which permits unrestricted use, distribution, and reproduction in any medium, provided the original author and source are credited. 
mitochondrial respiratory chain in cells [5]. During endogenous metabolic reactions, aerobic cells produce ROS, such as superoxide anion $(\mathrm{O} 2-)$, hydrogen peroxide $(\mathrm{H} 2 \mathrm{O} 2)$, hydroxyl radical $(\mathrm{OH} \bullet)$, and organic peroxides, as normal products of the biological reduction of molecular oxygen [6]. If ROS production increases beyond the threshold of this buffering capacity, these reactive species trigger uncontrolled reactions with non-target intracellular compounds, thus oxidizing nucleic acids, proteins, cellular membrane, and other lipids. Proteins and lipids are also significant targets for oxidative attack, and modification of these molecules can increase the risk of mutagenesis [7]. Increased levels of ROS cause oxidative stress and that severely damage lipids, proteins, and DNA [8].

Oxidative stress can activate a variety of transcription factors including nuclear factor kappa light chain enhancer of activated B cells $(\mathrm{NF}-\kappa \mathrm{B})$, AP1activator protein 1, p53, HIF-hypoxia-inducible factor $1 \alpha$, peroxisome proliferator-activated receptor $\gamma$ (PPAR- $\gamma$ ), $\beta$-catenin/Wnt, and Nrf2. Activation of these transcription factors can lead to the expression of over 500 different genes. Supraphysiologic levels of ROS that which exceed the capacity of the cellular radicalscavenging systems can cause oxidative stress and activate pro-inflammatory pathways [8]. ROS contribute to endothelial dysfunction and subsequent formation of atherosclerotic lesions [9]. Indeed, in vitro studies, as well as small in vivo trials, suggest that treatment with antioxidants chelators or antioxidative, enzymes might prevent ROS-mediated damage [8].

Previous studies had proposed that continuous oxidative stress can lead to chronic inflammation, which in turn could cause various chronic diseases. Increasing evidences in both experimental and clinical studies suggests that oxidative stress plays a major role in the pathogenesis of both types of diabetes mellitus [10]. Increased oxidative stress has been linked to impaired endothelial function in atherosclerosis and may play a role in the pathogenesis of cardiovascular events [11]. Endothelial dysfunction and increased vascular oxidative stress predict the risk of cardiovascular events in patients with coronary artery disease [11]. Endothelial dysfunction and increased vascular oxidative stress predict the risk of cardiovascular events in patients with coronary artery disease [12]. Furthermore, oxidative stress had been proposed to be involved in the pathogenesis of play role in many other diseases, such as cancer [7], neurological, and pulmonary diseases, age-related macular degeneration [13], systolic and diastolic heart failure [14], Alzheimer's disease (AD) [15], Parkinson's disease (PD) and amyotrophic lateral sclerosis [16], neurodegenerative diseases [17], microvascular and macrovascular complications in diabetic patients with diabetes [18], and cardiovascular events in patients with chronic kidney disease (CKD) [19].

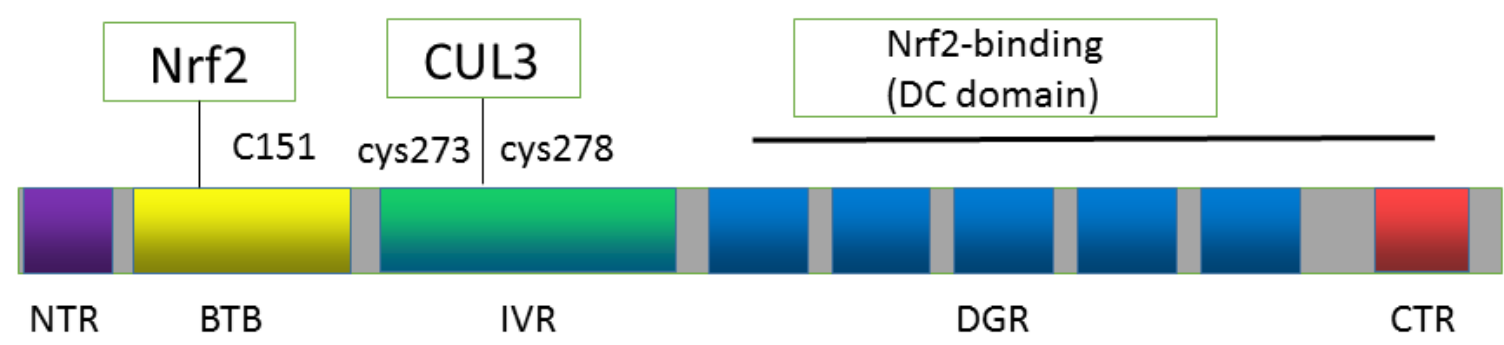

Figure 1. Domain structures of Keap1. Keap1 consists of three major functional domains: the BTB, IVR, and the Kelch/ $\beta$-propeller domains.

\section{Biology of Keap1/Nrf2/ARE pathway}

At the center of the day-to-day biological response to oxidative stress is the Kelch-like ECH-associated protein 1 (Keap1) - nuclear factor erythroid 2-related factor 2 (Nrf2) - antioxidant response elements (ARE) pathway, which regulates the transcription of numerous antioxidant genes that preserve cellular homeostasis and detoxification genes that process and eliminate carcinogens and toxins before they can cause damage.

\subsection{Keap1}

Keap1 is a 624-amino acid, cysteine-rich, homodimeric zinc-finger protein that functions as an adapter for Cul3Rbx E3 ubiquitin ligase complex (Fig. 1) [20]. Keap1 is composed by six domains, in which three are broad 
complex, tramtrack, bric-a-brac (BTB) domain, one is an intervening region (IVR), and two are glycine repeat domains (DGR) (Figure 1). Keap1 binds to the $\mathrm{N}$-terminal Neh2 domain of Nrf2 through its Kelch domain, and the BTB domain of Keap1 recruits Cul3. The binding of Nrf2 to the DGR domain is competitively inhibited by proteins with specific motifs such as p62 and partner and localizer of BRCA2 [21]. The IVR domain, in addition to its interaction with $\mathrm{Cul3}$ protein that contains the E3 ligase complex together with Roc1 [22], has a consensus sequence of nuclear export signal, which is important for localization of Keap1 at the cytoplasm [23]. Important cysteine residues for sensing electrophiles have been identified in the BTB (Cys151) and IVR (Cys273/288) domains [24].

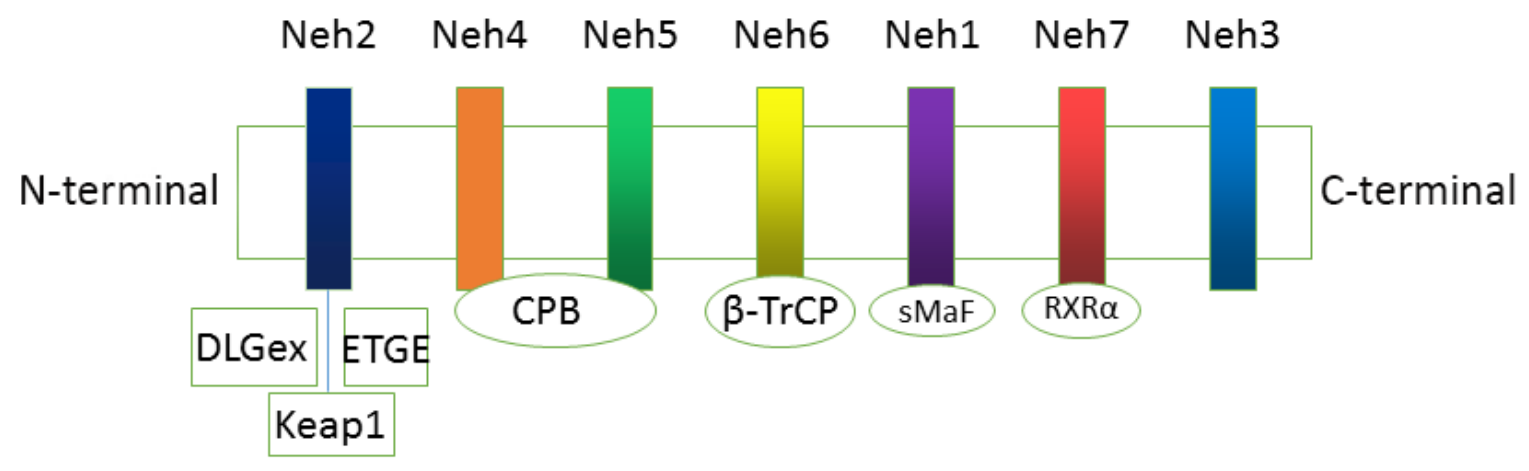

Figure 2. Domain structures of Nrf2. The Nrf2 protein contains7 domains, Neh1-Neh7. The ETGE and DLG motifs in the Neh2 domain are essential for the direct interaction with the Kelch domain of Keap1.

\subsection{Nrf2}

Nrf2 is a 605-amino acid transcription factor composed of seven functional domains (Neh1-7) (Fig. 2). The Nterminal Neh2 domain is the binding site for inhibitory protein Keap1, and it binds the Keap1 homodimer in two places [2]. It has a high affinity binding site with an ETGE motif and a low affinity site with a DLG motif separated by an alpha helix zone, which form the basis of the "latch and hinge" theory of Nrf2 activation [25-26]. The Neh1 domain, with its basic leucine zipper motif, allows the binding of Nrf2 to the ARE sequence [27-28]. The Cterminal of the Neh3 domain interacts with the transcription co-activator CHD6, which is a chromoATPase/helicase DNA-binding protein that is responsible for the transactivation of ARE-dependent genes after chromatin remodeling [29-31]. Neh4 and Neh5 represent domains of transcription activation that bind to the coactivator cyclic adenosine monophosphate (AMP)responsive element-binding protein and facilitate Nrf2 transcription [31]. In addition, Neh4 and Neh5 can also interact with the nuclear cofactor RAC3/AIB1/SRC-3 and enhance Nrf2-targeted ARE gene expression [29-31]. Neh7 domain interacts with retinoic $X$ receptor $\alpha$, thus repressing Nrf2 [32].

\subsection{Keap1/Nrf2/ARE pathway}

$\mathrm{Nrf} 2$ is a central player in the regulation of cellular defense mechanisms against environmental stresses [33]. Under normal physiological conditions, most Nrf2 is sequestered in the cytosol by its actin-bound inhibitor protein Keap1, a zinc metalloprotein that is localized near the plasma membrane [34-37]. Under oxidative stress, the Nrf2-Keap1 interaction is resolved in a dose-dependent manner, and the free and newly synthesized Nrf2 translocates to the nucleus and heterodimerizes with one of the small Maf (musculoaponeurotic fibrosarcoma oncogene homolog) proteins [38]. As shown in Figure 3, we propose that Nrf2/Maf complex activates the AREdependent gene expression of a series of antioxidative and cytoprotective proteins. Nrf2/Maf/ARE complex also play a physiological role through its anti-inflammatory, antioxidant, detoxification, autophagy, and proteasome actions.

Disruption of the interaction between Nrf2 and Keap1 is sufficient to trigger the activation of the Nrf2 pathway, as exemplified in the case of Nrf2 activation by the cyclindependent kinase inhibitor p21Cip/WAF1, which competes with Keap1 for binding to the DLG motif of Nrf2 and thereby protects Nrf2 from ubiquitination by opening the DLG latch [39]. p62 was identified as another protein that activates Nrf2 by disrupting the Keap1-Nrf2 interaction in autophagy-deficient cells (Fig. 3) [40]. Aside from Keap1, levels of active Nrf2 are regulated by autophagy and p62, which is a ubiquitin-binding protein 
acting as a scaffold for several protein aggregates and triggering their degradation through autophagy via the proteasome or the lysosome pathway [41]. p62 is degraded through autophagy under normal conditions. Oxidative stress upregulates p62 with resultant sequestration of Keap1 and activation of Nrf2 and Nrf2- dependent antioxidant defense gene expression [38]. In addition, protein kinase $\mathrm{C}$, mitogen-activated protein kinases, and phosphotidylinositol 3-kinase (PI3K) have been implicated in the regulation of Nrf2/ARE signaling (Fig. 3) [42].

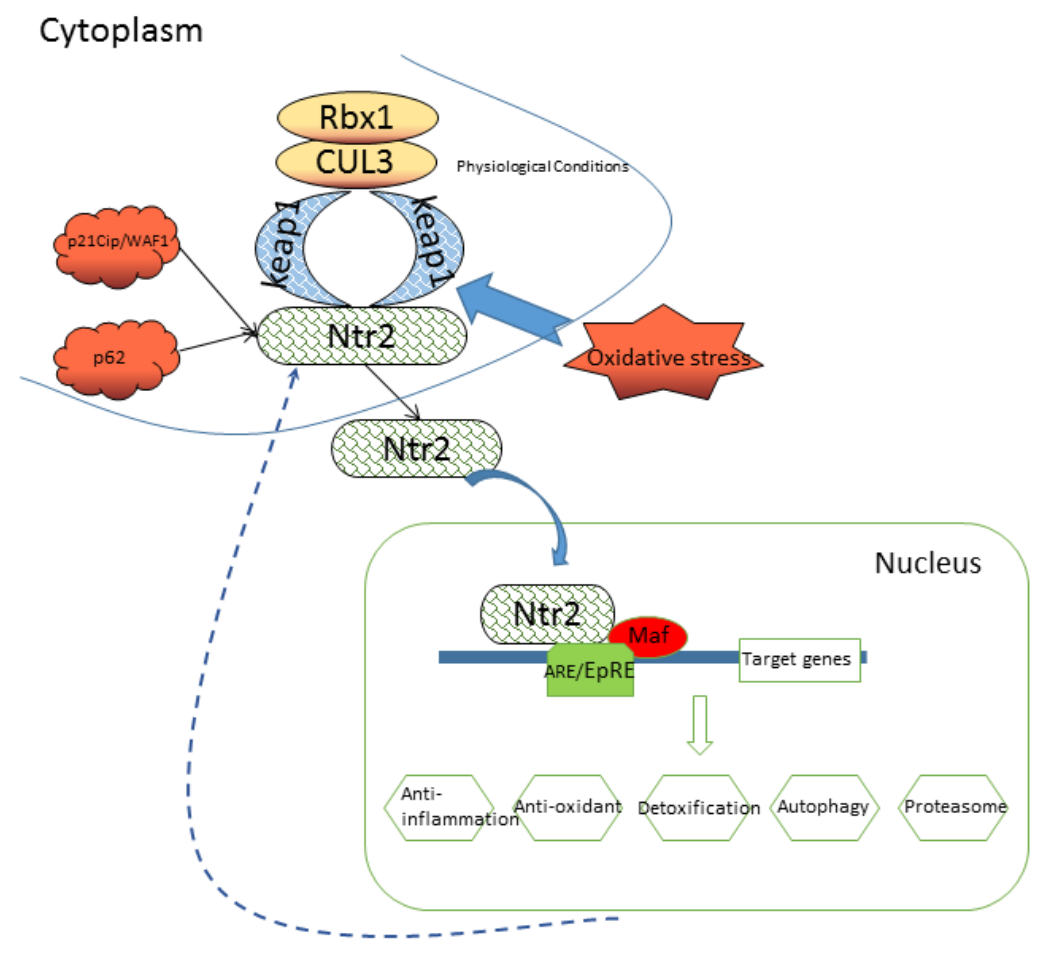

Figure 3. The Keap1-Nrf2-ARE pathway. Under physiological conditions, Nrf2 is restricted in the cytoplasm via its association with Keap1-Cul3-Rbx1 complex. In response to oxidative stress, $\mathrm{Nrf} 2$ is released from Keap1 translocates to the nucleus and heterodimerizes with one of the small Maf (musculoaponeurotic fibrosarcoma oncogene homolog) proteins. This complex activates the ARE-dependent gene expression of a series of antioxidative and cytoprotective proteins.

\subsection{Downstream target protein regulated by Keap1/Nrf2/ARE signaling pathway}

Nrf2 can evade Keap1-mediated degradation, translocate to the nucleus, and activate ARE-dependent gene expression of a series of antioxidative and cytoprotective proteins including heme oxygenase-1 (HO-1), NAD(P)H dehydrogenase, quinone 1 (NQO1), c-glutamylcysteine synthetase, glutathione peroxidase 1 , glutathionine $\mathrm{S}$ transferase (GST), glutathione reductase (GR), and superoxide dismutase (SOD) [43].

(1) Keap1/Nrf2/ARE regulates glutathione (GSH) levels by upregulating GSH synthetic and regenerative enzymes, including enzymes using GSH as a cofactor [2]. Glutamate cysteine ligase (GCL), including its two subunits GCLC and GCLM, catalyzes the rate-limiting step in GSH synthesis. Both GCLC and GCLM are upregulated by $\mathrm{Nrf2}$ [44].

(2) SOD is a metalloenzyme ( $\mathrm{Zn}, \mathrm{Cu}-\mathrm{SOD})$ that is stabilized by zinc using copper as the redox agent in the active site. Manganese is the redox agent in mitochondrial SOD.

(3) NAD $(\mathrm{P}) \mathrm{H}$ : NQO-1 is an inducible enzyme encoded by $N Q O 1$ gene. Recent work suggests that the Nrf2-Keap1 pathway regulates cytosolic and mitochondrial ROS production. Nrf2 deficiency leads to enhanced NAPDPH oxidase 2 activity and unrestricted Nrf2 activation, as knocking down Keap1 leads to enhanced NADPH oxidase 4 activity [45], which highlights the essential role of Nrf2-Keap1 pair in redox homeostasis and that of NADPH oxidase in regulating Nrf2 [46-47]. 
(4) HO-1, encoded by the HMOXl gene, is an inducible enzyme that catalyzes the freeing of hemebound $\mathrm{Fe}$ to form biliverdin. Biliverdin can then be reduced by biliverdin reductase to bilirubin, releasing carbon monoxide $(\mathrm{CO})$ and exerting its anti-inflammatory effect. A previous study showed that the Nrf2-ARE pathway and its downstream antioxidant enzyme HO-1 are crucial for melanocytes to cope with $\mathrm{H} 2 \mathrm{O} 2-$ induced oxidative damage [48].

(5) Catalase is a highly efficient enzyme that reduces $\mathrm{H} 2 \mathrm{O} 2$ to water and oxygen using $\mathrm{Fe}$ in the catalytic site [49-50].

(6) Thioredoxin (Trx) is a protein disulfide reductase that is itself reduced by thioredoxin reductase (TrxR) [51]. Nrf2 and the oxidoreductase thioredoxin-1 (Trx-1) have been previously identified as protective factors in cardiovascular disorders, with Trx-1 stimulating oxidative phosphorylation and tricarboxylic acid cycle via peroxisome proliferator-activated receptor gamma coactivator $1 \alpha$ and $\mathrm{Nrf} 2$ in cardiomyocytes and Nrf2 stimulating Trx-1 expression [52-53].

(7) In addition to direct upregulation of AREresponsive genes, Nrf2 also supports antioxidant and detoxification pathways by increasing the synthesis and regeneration of NADPH, which is a niacin-derived reducing agent. NADPH is a direct antioxidant and is used as an enzyme cofactor in many redox reactions such as in GSH reduction by GR [54-55].

(8) Nrf2-deficient mice are more susceptible to benzo $[\alpha]$ pyrene-induced tumor formation, thus suggesting that Nrf2 is essential for a complete phase II metabolism [56]. Furthermore, the role of Nrf2 system in phase I-related genes and phase III xenobiotic transporters had also been proposed [57]. Nrf2 might play a role in the whole process of xenobiotic metabolism. Collectively, defending against xenobiotic metabolism and providing an efficient antioxidant system, $\mathrm{Nrf} 2$ can be considered as one of the main factors contributing to animal evolution in a changing environment [38]. On the other hand, the Nrf2/Keap1 system can be epigenetically regulated by DNA methylation, histone modification, and microRNAs, which add another layer of complexity to Nrf2 regulation and function [58].

(9) Nrf2 and NF-kB pathways regulate the physiological homeostasis of cellular redox status and responses to stress and inflammation [38]. Previous studies have suggested that Nrf2 plays a role in counteracting NF- $\mathrm{BB}$-driven inflammatory response in many experimental models [59-61]. Rac1, which is activated by lipopolysaccharides, stimulates NF- $\kappa B$ to induce Nrf2, which in turn upregulates HO-1 expression. Then, HO-1 reduces the NF- $\mathrm{KB}$ inflammatory activity and shifts the cells to a more reducing environment that is essential for terminating the NF- $\mathrm{KB}$ activation [62-63].

\section{Keap1/Nrf2/ARE pathway and disease implication}

Keap1/Nrf2/ARE pathway represents one of the most important cellular defense mechanisms against oxidative stress and xenobiotic damage [64]. The Keap1/Nrf2/ARE pathway plays a major role in health resilience including inflammatory diseases [65], neurodegenerative diseases [66], PD [67], AD [68], stroke [69], chronic kidney disease [70], atherosclerosis [71], diabetes [72], cardiovascular diseases [73] and rheumatoid arthritis [74].

\subsection{Exercise}

By scavenging excessive ROS levels and restoring redox homeostasis, Nrf2 can prevent age-related muscular disorders and play a crucial role in response to training exercise [38]. In addition, uncontrolled Nrf2 activation can produce harmful consequences: In autophagic muscle disorders, Nrf2 is persistently activated with negative consequences on organ functions. Some studies had proposed that both resistance and endurance muscle exercises can lead to a perturbation of cellular redox homeostasis by increasing ROS and reactive nitrogen species [75-76]. Both in vitro (C2C12 skeletal muscle cells) and in vivo (rodent muscles) studies confirmed that oxidative stress can activate Nrf2 gene expression and transcriptional activity [75-79].

In young and older men, it has been shown that acute exercise can increase Nrf2 protein levels in peripheral blood mononuclear cells [80]. Moreover, nuclear accumulation of Nrf2 was observed only in the young group, thus indicating that aging is accompanied by a reduced nuclear import of Nrf2 [81-82]. Indeed, young animals showed no changes in Nrf2 expression, whereas older animals responded to the same training regimen with a decrease in Nrf2 [83]. Compared to young animals, older animals showed marked increases in baseline levels of Nrf2 expression [84]. Thus, it is plausible that resistance exercises, by restoring the redox homeostasis, lower Nrf2 basal levels. On the whole, exercise is an eligible routine to improve endogenous antioxidant defenses via Nrf2 activation. However, whether or not exogenous supplementation of antioxidants/Nrf2 activators during muscle adaptation is beneficial is still disputed [85-86]. Recent work has shown that the Nrf2 activator sulforaphane (SFN) enhances running capacity in rats by upregulating Nrf2 signaling and downstream genes and attenuates muscle fatigue via reduction of oxidative stress caused by exhaustive exercise [87]. Studies of Nrf2 activation as a response to resistance training produced less defined results, hence prompting further investigation. 
Oxidative stress has long been implicated in the genesis of sarcopenia. ROS-activated NF-kB in myoblasts induces the expression of receptors for advanced glycation end-products (RAGE) that are required for timely muscle regeneration of acutely injured muscles, with the antioxidant $\mathrm{N}$-acetyl cysteine reducing NF- $\mathrm{KB}$ activation and RAGE expression [88]. Moreover, Nrf2 transcriptionally upregulates carbonyl reductase 1 , which plays a critical role in controlling redox balance and detoxifying lipid peroxidation during muscle differentiation and regeneration [89]. Lastly, mitochondrial ROS signaling repairs exercise-injured myofibers via RhoA-mediated F-actin assembly at injured sites [90]. Notably, Nrf2 activity was reported to reduce muscle glycogen content with resultant improved glucose tolerance via upregulation of the glycogen branching enzyme and muscle-type $\mathrm{PhK} \alpha$ subunit mRNAs [38]. The protective effect of $\mathrm{Nrf} 2$ antioxidant pathway stimulation has been reported in other experimental settings such as in neuroinflammation [91].

\subsection{Cardiovascular system}

Oxidative stress plays a major role in the pathophysiology of cardiac disorders [92]. Several studies have highlighted the cardinal role played by ROS or RNS overproduction in the pathogenesis of ischemic myocardial damage and consequent cardiac dysfunction [93]. A previous study indicated that elevation of Tsg101 levels could be protective against myocardial ischemia/reperfusion (I/R) injury by activating the p62-Keap1-Nrf2 signaling [94]. A review summarized evidences from clinical studies and animal experiments relating to the potential mechanisms by which SFN modulates Nrf2 activation and protects against cardiovascular diseases [93]. Moreover, a series of studies reported that interventions against endoplasmic reticulum (ER) stress and Nrf2 activation reduce myocardial infarct size and cardiac hypertrophy in the transition to Heart failure (HF) in animals exposed to I/R injury and pressure overload, respectively [95]. Nonetheless, a negative side of Nrf2 had been proposed: when Nrf2 is over activated, it can cause and not prevent cardiovascular diseases [96]. Mounting evidence has strongly implicated oxidative stress in the development of cardiac dysfunction, and myocardial apoptosis contributes to the pathogenesis of heart failure [97]. ROS-mediated mitochondrial damage and cardiomyocyte apoptosis progress through modulations of Keap1-Nrf2 signaling axis [97]. A previous study demonstrated that butein and phloretin upregulate HO-1 and GCL expression through the ERK2/Nrf2 pathway and protect hepatocytes against oxidative stress [98]. Nrf2 activation in ischemia and I/R injury is being considered protective towards cardiomyocytes [38]. Nrf2 has been reported to operate downstream of NADPH oxidase-4, which is an important modulator of redox signaling that activates Nrf2-regulated pathway to regulate GSH redox in cardiomyocytes and to protect the heart in chronic hypertension [99-100]. Cardiac-specific Nrf2 knockout mice exhibited significantly dampened anti-apoptotic effects of tanshinone IIA sulfonate [97].

\subsection{Diabetes and diabetic complications}

In diabetes, oxidative stress impairs glucose uptake in muscles and fats and decreases insulin secretion from pancreatic cells [101-102]. Numerous evidences have recently elucidated the role of Keap1-Nrf2 system in metabolic and energy-balance regulation [103].

\subsubsection{Oxidative stress damages pancreatic $\beta$-cells}

Oxidative stress is enhanced in pancreatic islets of rodent models of diabetes, $\mathrm{db} / \mathrm{db}$ mice, and Goto-Kakizaki rats [103]. A previous study reported that oxidative stress is increased in pancreatic islets of patients with diabetes [104]. Antioxidant reagents improve insulin secretion from pancreatic islets and ameliorate pancreatic b-cell damage in rodent diabetic models [105-106]. Thus, enhancement of antioxidant enzymes may be a useful strategy for pancreatic b-cell protection.

\subsubsection{The Keap1-Nrf2 system in blood glucose homeostasis}

The antioxidant function of the Keap1-Nrf2 system plays an important role in the maintenance of glucose metabolism through both insulin secretion and glucose utilization in insulin-sensitive tissues [103]. It has been reported that Nrf2 also regulates lipid metabolism-related genes [107]. Thus, Nrf2 plays an important role in maintaining glucose homeostasis in animal models [103]. Previous studies indicated that the Keap1-Nrf2 system did function in pancreatic b-cells and that Nrf2 regulates antioxidant enzyme gene transcription in pancreatic bcells [103].

\subsubsection{The Keap1-Nrf2 system protects pancreatic b- cells against stress through multiple critical pathways}

First, the Nrf2-mediated antioxidant response is crucial for pancreatic b-cell protection against ROS/RNS and xenobiotics [108]. Second, the Nrf2-inducer SFN strongly suppresses cytokine-mediated iNOS and COX-2 induction, thereby ameliorating pancreatic b-cell damage [109]; thus, Nrf2 contributes to the suppression of inflammation in pancreatic b-cells. Third, Nrf2 also plays an important role in the maintenance of autophagy in 
pancreatic b-cells [110]. Fourth, Nrf2 regulates the expression of proteasome catalytic subunits and contributes to the ER stress response in pancreatic b-cells [111]. Finally, Nrf2 inducers enhance the phosphorylation of AMP-activated protein kinase (AMPK) and increase glucose uptake while suppressing glucose production in the liver, indicating that Nrf2 induction modulates AMPK signaling and improves insulin resistance [112]. In addition, previous findings suggest that activation of the Keap1-Nrf2 signaling pathway provokes anti-obesity effects, which may be an additional benefit in the clinical use of this pathway [103].

Several reports have claimed that Nrf2 depletion suppresses insulin resistance and obesity according to analysis of Nrf2 knockout mice. Blood glucose levels of Nrf2 knockout mice were lower than those of wild-type mice, and insulin signaling is enhanced in Nrf2 knockout mouse liver and skeletal muscle [103, 113]. However, some other studies found that Nrf2 depletion increased blood glucose levels [114]. Thus, multiple approaches are essential to elucidate the full array of Nrf2 functions.

\subsubsection{Diabetic complications and the Keap1-Nrf2 system}

Nrf2 depletion increases renal oxidative and nitrosative stress in streptozotocin (STZ)-induced mouse diabetes model [115]. Nrf2 also helps to prevent diabetic retinopathy and cardiomyopathy. In the STZ-induced diabetic model, the Keap1-Nrf2 system helped to protect against the onset and/or progression of diabetic retinopathy [116]. In addition, the Nrf2 inducer dihydroCDDO-TFEA suppressed diabetes-mediated cardiac nitrosative damage [117].

\subsection{Cancer}

Comprehensive genomic analyses have found somatic mutations and other alterations in the $K E A P 1$ or $N R F 2$ genes and in well-known tumor suppressor genes or oncogenes, such as TP53, CDKN2A, $P T E N$, and PIK3CA, in various types of cancer [118]. Several studies have shown that Nrf2-Keap1 pathway protects against oxidative stress [119], chemotherapeutic agents [120], and radiotherapy [121] in cancer. However, Nrf2 disruption can also lead to the progression of inflammation and, ultimately, cancer formation [122]. Jeong et al. [123] found that KEAPI/Nrf2 mutations increase radio resistance and predict local tumor recurrence in patients undergoing radiotherapy. Thus, this phenomenon is known as a 'double-edged sword', with respect to the benefits or risks of the Keap1-Nrf2 pathway in cells [124]. The discovery of the dual role of Nrf2-Keap1 pathway enabled scientists to understand
Nrf2 signaling in cancer and to develop pharmacological compounds targeting $\mathrm{Nrf} 2$ for the prevention and treatment of cancer [122].

Elevated levels of Nrf2 in cancer cells can lead to: (1) Somatic mutations: gain-of-function mutations in Nrf2 and loss-of-function mutations in Keap1 and CUL3 have been identified in several human malignancies [122]. Somatic mutations in CUL3 were identified in cases of hereditary type 2 papillary renal cell carcinoma [125]; (2) Epigenetic silencing of Keap1 by hypermethylation: Methylation in the promoter region of Keap1 alters its expression and prevents its ability to bind with Nrf2. Conversely, DNA methylation by DNA methyltransferases appears to indirectly downregulate Nrf2 expression [126-127]; (3) Accumulation of p21 and p62 disrupts the Nrf2-Keap1 complex: p53 negatively regulates Nrf2 [128]. p21, which is a direct downstream target of p53, associates with the DLG motif of Nrf2, leading to the disruption of Keap1 binding with Nrf2. Furthermore, p62 directly interacts with the kelch domain of Keap1 by its STGE motif that is similar to the Nrf2 ETGE motif, thereby disrupting the Keap1-Nrf2 complex [122]; (4) Transcriptional upregulation of $\mathrm{Nrf2}$ by oncogenes: Oncogenes like $K R A S, B R A F$, and $C-M Y C$ increase mRNA levels of Nrf2 and its target genes [129]; (5) Metabolic activation of Nrf2 by Kreb cycle intermediates: Kreb's cycle leads to prolonged activation of Nrf2 [130].

\subsection{Neurodegenerative disorders}

The protective effect of Nrf2 against neurodegeneration caused by oxidative stress has been well proposed. Studies on neurodegenerative diseases have found that activation of $\mathrm{Nrf} 2$ protects against $\mathrm{H} 2 \mathrm{O} 2$-induced $\mathrm{PC} 12$ cell death and apoptosis [131-132].

\subsubsection{Alzheimer's disease}

$\mathrm{AD}$ is a progressive neurodegenerative disease characterized by insidious cognitive decline and memory dysfunction. Studies have shown that the expression of Nrf2 target genes were increased in AD patients [122]. One study provided a strong evidence that direct Keap1Nrf2 disruptors can specifically target the defects in Nrf2 activity observed in AD [133]. Another study showed a clear link between Nrf2 and AD-mediated cognitive decline, thus further strengthening the connection between Nrf2 and AD [134]. Furthermore, Lipton et al. [135] concluded that carnosic acid exhibits therapeutic benefits in rodent $\mathrm{AD}$ models by stimulating the Keap1/Nrf2 transcriptional pathway. The neuroprotective role of Nrf2 in AD had been mainly proposed through GSK-3 $\beta$ in the regulation of the Nrf2 pathway [136]. 
Therefore, the activation of Nrf2 could be a therapeutic target for $\mathrm{AD}$ and could potentially ameliorate this disease.

\subsubsection{Parkinson's disease}

PD is a type of movement disorder, and it occurs when neurons in the brain do not produce enough dopamine. Activation of NOQ1 and HO-1, through Nrf2 nuclear localization, was induced in the substantia nigra of PD patients [137]. One study suggested that safranal protects against rotenone-induced neurotoxicity associated with the Nrf2 signaling pathway. This implies that safranal may be a potential therapeutic drug for the treatment of PD [138]. A link has been revealed between the transcription factor NRF2 and PD at genetic level; and it was shown that a functional haplotype in the human NFE2L2 gene promoter of NRF2, with slightly increased transcriptional activity, is associated with decreased risk and delayed age of onset of PD [139]. However, another study reported that NRF2 mRNA expression levels did not correlate with the rs35652124 genotype, PD, or age of onset in our material [140]. Furthermore, Lastres-Becker et al. [141] provided a compelling rationale for targeting NRF2 with dimethyl fumarate as a therapeutic strategy to reinforce endogenous brain defense mechanisms against PD-associated synucleinopathy.

\subsection{Stroke}

ROS has been widely reported to play a key role in the pathological process of ischemic stroke followed by reperfusion [142]. The role of Nrf2 in ischemic and hemorrhagic stroke had been proposed [143]. A previous study showed that recombinant human erythropoietin activates Keap1-Nrf2/ARE pathway after ischemia to protect the brain tissue [144]. Another study found that treatment with myricetin attenuates brain injury and neurological deficits in a rat model with cerebral ischemia by improving mitochondrial function and activating Nrf2 pathway [145]. Similarly, it was observed that in a mice model, hybrids (HP)-1c, with dual AMPK- and Nrf2-activating properties, may be potential subjects of further studies as novel therapy for ischemic stroke [146]. Loss of Nrf2 function increases the size of cerebral infarct and neurological deficits after an ischemic event [142]. Accumulating data suggest that the loss of Nrf2 exacerbates cerebral infarction and neurologic deficits in both middle cerebral artery occlusion (MCAO) and permanent MCAO models [147-150]. In addition, Nrf2 knockdown in endothelial cells significantly aggravated delocalization of the tight junction-associated protein $\mathrm{ZO}$ 1 during ischemic conditions, hence indicating the protective role of $\mathrm{Nrf} 2$ in blood-brain barrier integrity
[151]. Thus, Nrf2 activation may protect neurons, astrocytes, oligodendrocytes, and microglia against oxidative stress; thus, the Keap1-Nrf2 pathway is suggested as one of the therapeutic approaches to the neurovascular system [122].

\subsection{Liver and kidney system diseases}

A previous study found that Nrf2 activation prevents alcohol-induced oxidative stress and accumulation of free fatty acids in liver by increasing genes involved in antioxidant defense and by decreasing genes involved in lipogenesis [152]. Another study confirmed that pretreatment with SFN could attenuate hepatic I/R injury via the activation of Nrf2/ARE signaling pathways, ameliorate oxidative stress, and maintain the normal activities of $\mathrm{Na}+-\mathrm{K}+-$ ATPase and $\mathrm{Ca} 2+-\mathrm{ATPase}$, thus reducing the occurrence of cell oncogenesis and apoptosis [153]. Shen et al. indicated that p62-Keap1-Nrf2 antioxidant pathway was primarily activated in the early stage of acetaminophen hepatotoxicity, which might play a protective role in the process of acetaminophen-induced acute liver injury [154]. In addition, therapeutic approaches to prevent oxidative stress via activation of the Nrf2-Keap1 signaling and/or suppression of uremic toxin-induced ROS production could be effective strategies for maintaining optimal kidney function [19].

\subsection{Low-level laser irradiation, Oxidative stress and Keap1/Nrf2/ARE pathway}

Low-level laser irradiation (LLLI) has gained increasing popularity as a treatment for soft tissue injuries and joint conditions [155]. It is applied transcutaneously with typical irradiances of $10-5,000 \mathrm{~mW} / \mathrm{cm} 2$, treatments times ranging from 10 seconds to 2 minutes, and with total energy of 1-4 Joules $(\mathrm{J}) / \mathrm{cm} 2$ per point delivered when targeting joints, tendons, and muscles [156]. Its application includes wound healing, healing of soft and hard tissues [157], and treating pain syndromes, enthesopathy, peripheral nerve injury, traumatic brain injury [158], and peripheral neuropathy, thus improving muscular performance [159]. LLLI modulates many biological processes, manifesting as an increase in mitochondrial respiration and in ATP synthesis proliferation of mesenchymal and cardiac stem cells [160]. The anti-inflammatory qualities of LLLI had also been suggested [161]. However, the biological effect of LLLI is still not well understood and is still controversial [162].

LLLI might play a role in the mitochondria, leading to increased ATP production, ROS modulation, and transcription factors induction. These effects, in turn, lead to increased cell proliferation and migration, particularly 
by fibroblasts [163]. Furthermore, previous studies in animal and human cell lines had proposed that LLLI play a role in anti-inflammatory and anti-oxidative stress responses [164-172]. (1) At the cellular level: Macedo et al. [164] suggested that the laser treatment improved regenerative capacity and decreased inflammatory response and oxidative stress in dystrophic muscle cells. Furthermore, Lubart et al. [165] demonstrated that various ROS and antioxidants were produced following lowenergy visible light illumination. Similarly, Souza et al. [166] reported that LLLI acts by decreasing cytokines and histone deacetylase through the activation of protein kinase A via inhibition of PI3K in U937 cells. (2) In animal models: In both nondiabetic and diabetic rat models, LLLI was observed to possibly play pivotal roles in promoting wound healing process by improving glycemic state, cytokines involved in inflammation, and antioxidant defense system [167]. Another study indicated that LLLI therapy was efficient in accelerating skin wound healing process after wounding, and this is probably due to reduction of the inflammatory phase and induction of collagen synthesis in an animal model [168]. Furthermore, LLLI could be an effective therapeutic approach in modulating oxidative and nitrative stress and in reducing inflammation in rats with injured muscles [169]. Another study found that the effect of laser in attenuating acute lung inflammation restores the balance between the pro- and antioxidants mediators such as PPARy expression and consequently heat shock protein 70 production in rats [170]. (3) In human models: De Marchi et al. [171] found that the use of LLLI before progressive-intensity running exercise increases exercise performance and decreases exercise-induced oxidative stress and muscle damage in humans. Another study reported that LLLI reduced oxidative stress in neural and muscular tissues of non-obese volunteers [172].

Given the role of Keap1-Nrf2-ARE pathway and its anti-inflammatory and anti-oxidant effects, we hypothesize that the anti-inflammatory and anti-oxidant mechanisms of LLLI may be achieved by activating the Keap1/Nrf2/ARE signaling pathway. Hence, this would be the focus of our future research.

\section{Conclusions}

In this study, we review and discuss recent advancements in the regulation of the Keap1/Nrf2/ARE system and its role under physiological and pathophysiological conditions such as in exercise, diabetes, cardiovascular diseases, cancer, neurodegenerative disorders, stroke, liver and kidney system, etc. The redox-sensitive signaling system Keap1/Nrf2/ARE plays a key role in maintenance of cellular homeostasis under stress and in inflammatory, carcinogenic, and pro-apoptotic conditions, thus allowing us to consider this system as a pharmacological target. Furthermore, we also suggest LLLI as a potential therapeutic target to oxidative stress by regulating the Keap1/Nrf2/ARE system.

\section{Acknowledgements}

This study was supported by grants from CAMS Innovation Fund for Medical Science (No. 2017-I2M-1016) and National Natural Science Foundation of China (Grant No. 81602800)

\section{Conflict of Interest Disclosures}

None

\section{References}

[1] Sies H (2015). Oxidative stress: a concept in redox biology and medicine. Redox biology, 4: 180-3.

[2] Stefanson A L, Bakovic M (2014). Dietary regulation of Keap1/Nrf2/ARE pathway: focus on plant-derived compounds and trace minerals. Nutrients, 6: 3777-801.

[3] Durackova Z (2010). Some current insights into oxidative stress. Physiol Res, 59: 459-69.

[4] Jabs T (1999). Reactive oxygen intermediates as mediators of programmed cell death in plants and animals. Biochem Pharmacol, 57:231-45.

[5] Poyton RO, Ball KA, Castello PR (2009). Mitochondrial generation of free radicals and hypoxic signaling. Trends Endocrinol Metab, 20:332-40.

[6] Fridovich I (1978). The biology of oxygen radicals. Science, 201:875-80.

[7] Reuter S, Gupta SC, Chaturvedi MM, Aggarwal BB (2010). Oxidative stress, inflammation, and cancer: how are they linked? Free Radic Biol Med, 49: 1603-16.

[8] Dreger H, Westphal K, Wilck N, Baumann G, Stangl V, Stangl K, et al. (2009). Protection of vascular cells from oxidative stress by proteasome inhibition depends on Nrf2. Cardiovasc Res, 85: 395-403.

[9] Madamanchi NR, Vendrov A, Runge MS (2005). Oxidative stress and vascular disease. Arterioscler Thromb Vasc Biol, 25:29-38.

[10] Maritim AC, Sanders RA, Watkins JB (2003). Diabetes, oxidative stress, and antioxidants: a review. J Biochem Mol Toxicol,17: 24-38.

[11] Heitzer T, Schlinzig T, Krohn K, Meinertz T, Münzel T (2001). Endothelial dysfunction, oxidative stress, and risk of cardiovascular events in patients with coronary artery disease. Circulation, 104: 2673-8.

[12] Giacco F, Brownlee M (2010). Oxidative stress and diabetic complications. Circ Res, 107: 1058-70.

[13] Beatty S, Koh H H, Phil M, Henson D, Boulton M (2000). The role of oxidative stress in the pathogenesis of age-related macular degeneration. Surv Ophthalmol, 45: 115-34.

[14] Münzel T, Gori T, Keaney Jr JF, Maack C, Daiber A (2015). Pathophysiological role of oxidative stress in 
systolic and diastolic heart failure and its therapeutic implications. Eur Heart J 36: 2555-64.

[15] Wang X, Wang W, Li L, Perry G, Lee HG, Zhu X (2014). Oxidative stress and mitochondrial dysfunction in Alzheimer's disease. Biochim Biophys Acta, 1842: 1240-7.

[16] Barnham KJ, Masters CL, Bush AI (2004). Neurodegenerative diseases and oxidative stress. Nat Rev Drug Discov, 3: 205.

[17] Kim G H, Kim J E, Rhie S J, Yoon S (2015). The role of oxidative stress in neurodegenerative diseases. Exp Neurobiol, 24: 325-40.

[18] Giugliano D, Ceriello A, Paolisso G (1996). Oxidative stress and diabetic vascular complications. Diabetes care, 19: 257-67.

[19] Saito H (2013). Toxico-pharmacological perspective of the Nrf2-Keap1 defense system against oxidative stress in kidney diseases. Biochem Pharmacol, 85: 865-72.

[20] Cullinan SB, Gordan JD, Jin J, Harper JW, Diehl JA (2004). The Keap1-BTB Protein Is an Adaptor That Bridges Nrf2 to a Cul3-Based E3 Ligase: Oxidative Stress Sensing by a Cul3-Keap1 Ligase. Mol Cell Biol, 24: 8477-886

[21] Fuse Y, Kobayashi M (2017). Conservation of the Keap1-Nrf2 system: An evolutionary journey through stressful space and time. Molecules, 22: 436.

[22] Furukawa M, Xiong Y (2005). BTB protein Keap1 targets antioxidant transcription factor $\mathrm{Nrf} 2$ for ubiquitination by the Cullin 3-Roc1 ligase. Mol Cell Biol, 25: 162-71.

[23] Velichkova M, Hasson T (2005). Keap1 regulates the oxidation-sensitive shuttling of Nrf2 into and out of the nucleus via a Crm1-dependent nuclear export mechanism. Mol Cell Biol, 25:4501-13.

[24] Itoh K, Wakabayashi N, Katoh Y, shii T, Igarashi K, Engel JD, et al. (1999). Keap1 represses nuclear activation of antioxidant responsive elements by Nrf2 through binding to the amino-terminal Neh2 domain. Genes Dev, 13: 76-86.

[25] Tong KI, Padmanabhan B, Kobayashi A, Shang C, Hirotsu Y, Yokoyama S, et al. (2007). Different Electrostatic Potentials Define ETGE and DLG Motifs as Hinge and Latch in Oxidative Stress Response. Mol Cell Biol, 27: 7511-21.

[26] Hast BE, Goldfarb D, Mulvaney KM, Hast MA, Siesser PF, Yan F, et al. (2013) Proteomic Analysis of Ubiquitin Ligase KEAP1 Reveals Associated Proteins That Inhibit NRF2 Ubiquitination. Cancer Res, 73: 2199-210.

[27] Itoh K1, Chiba T, Takahashi S, Ishii T, Igarashi K, Katoh Y, et al. (1997). An Nrf2/Small Maf Heterodimer Mediates the Induction of Phase II Detoxifying Enzyme Genes through Antioxidant Response Elements. Biochem Biophys Res Commun, 236: 313-22.

[28] Keum YS, Choi BY (2014). Molecular and chemical regulation of the Keap1-Nrf2 signaling pathway. Molecules, 19: 10074-89.

[29] Namani A, Li Y, Wang XJ, Tang X (2014). Modulation of NRF2 signaling pathway by nuclear receptors: implications for cancer. Biochim Biophys Acta, 1843: 1875-85
[30] Krajka-Kuźniak V, Paluszczak J, Baer-Dubowska W (2017). The Nrf2-ARE signaling pathway: an update on its regulation and possible role in cancer prevention and treatment. Pharmacol Rep, 69: 393-402.

[31] Xiang MJ, Namani A, Wu SJ, Wang X (2014). Nrf2: bane or blessing in cancer? J Cancer Res Clin Oncol, 140: 1251-9.

[32] Bai X, Chen Y, Hou X, Huang M1, Jin J (2016). Emerging role of NRF2 in chemoresistance by regulating drug-metabolizing enzymes and efflux transporters[J]. Drug Metab Rev, 48: 541-67.

[33] Kensler TW, Wakabayashi N, Biswal S (2007). Cell survival responses to environmental stresses via the Keap1-Nrf2-ARE pathway. Annu Rev Pharmacol Toxicol, 47: 89-116.

[34] Kang MI, Kobayashi A, Wakabayashi N, Kim SG, Yamamoto M (2004). Scaffolding of Keap1 to the actin cytoskeleton controls the function of $\mathrm{Nrf} 2$ as key regulator ofcytoprotective phase 2 genes. Proc. Natl. Acad. Sci. USA, 101: 2046-51.

[35] Adams J, Kelso R, Cooley L (1999). The kelch repeat superfamily of proteins: Propellers of cell function. Trends Cell Biol, 10: 17-24.

[36] Dinkova-Kostova AT, Holtzclaw WD, Wakabayashi N (2005). Keap1, the Sensor for Electrophiles and Oxidants that Regulates the Phase 2 Response, Is a Zinc Metalloprotein. Biochemistry, 44: 6889-99.

[37] Velichkova M, Hasson T (2003). Keap1 in Adhesion Complexes. Cell Motil Cytoskelet, 56: 109-19.

[38] Bellezza I, Giambanco I, Minelli A, Donato R (2018). Nrf2-Keap1 signaling in oxidative and reductive stress. Biochimica et Biophysica Acta, 1865: 721-33.

[39] Chen W, Sun Z, Wang XJ, Jiang T, Huang Z, Fang D, et al. (2009). Direct interaction between Nrf2 and p21(Cip1/WAF1) upregulates the Nrf2-mediated antioxidant response. Mol Cell, 34: 663-73.

[40] Komatsu M, Kurokawa H, Waguri S, Taguchi K, Kobayashi A, Ichimura Y, et al. (2010). The selective autophagy substrate p62 activates the stress responsive transcription factor Nrf2 through inactivation of Keap1. Nat Cell Biol, 12: 213-23.

[41] Bjorkoy G, Lamark T, Johansen T (2006). p62/SQSTM1: a missing link between protein aggregates and the autophagy machinery. Autophagy, 2: 138-9.

[42] Mann GE, Niehueser-Saran J, Watson A, Gao L, Ishii T, de Winter P, et al. (2007). Nrf2/ARE regulated antioxidant gene expression in endothelial and smooth muscle cells in oxidative stress: implications for atherosclerosis and preeclampsia. Sheng Li Xue Bao, 59: 117-27.

[43] Magesh S, Chen Y, Hu L (2012). Small molecule modulators of Keap1-Nrf2-ARE pathway as potential preventive and therapeutic agents. Med Res Rev, 32:687-726.

[44] Shelly C (2009). Lu Regulation of glutathione synthesis. Mol Asp Med, 30: 42-59.

[45] Kovac S, Angelova PR, Holmström KM, Zhang Y, Dinkova-Kostova AT, Abramov AY (2015). Nrf2 
regulates ROS production by mitochondria and NADPH oxidase. Biochim Biophys Acta, 1850: 794-801.

[46] Brewer AC, Murray TVA, Arno M, Zhang M, Anilkumar NP, Mann GE, et al. (2011). Nox4 regulates Nrf2 and glutathione redox in cardiomyocytes in vivo. Free Radic Biol Med, 51: 205-15.

[47] Papaiahgari S, Kleeberger SR, Cho HY, Kalvakolanu DV, Reddy SP (2004). NADPH oxidase and ERK signaling regulates hyperoxia-induced Nrf2-ARE transcriptional response in pulmonary epithelial cells. J Biol Chem, 279: 42302-12.

[48] Jian Z, Li K, Liu L, Zhang Y, Zhou Z, Li C, et al. (2011). Heme oxygenase-1 protects human melanocytes from $\mathrm{H}(2) \mathrm{O}(2)$-induced oxidative stress via the Nrf2-ARE pathway. J Invest Dermatol, 131:1420-7.

[49] Matés JM (2000). Effects of antioxidant enzymes in the molecular control of reactive oxygen species toxicology. Toxicology, 153: 83-104.

[50] Zhang DD, Hannink M (2003). Distinct Cysteine Residues in Keap1 Are Required for Keap1-Dependent Ubiquitination of $\mathrm{Nrf} 2$ and for Stabilization of Nrf2 by Chemopreventive Agents and Oxidative Stress. Mol Cell Biol, 23: 8137-51.

[51] Mustacich D, Powis G (2000). Thioredoxin reductase. Biochem J, 346: 1-8.

[52] Jakobs P, Serbulea V, Leitinger N, Eckers A, Haendeler J (2017). Nuclear factor (erythroid-derived 2)-like 2 and thioredoxin-1 in atherosclerosis and ischemia/reperfusion injury in the heart. Antioxid Redox Signal, 26: 630-44.

[53] Tsai CY, Wang CC, Lai T, Tsu HN, Wang CH, Liang HY, et al. (2013). Antioxidant effects of diallyl trisulfide on high glucose-induced apoptosis are mediated by the PI3K/Akt-dependent activation of Nrf2 in cardiomyocytes. Int J Cardiol, 168: 1286-97.

[54] Kim JE, You DJ, Lee C, Ahn C, Seong JY, Hwang JI. (2010). Suppression of NF-kappaB signaling by Keap1 regulation of IKK-beta activity through autophagic degradation and inhibition of phosphorylation. Cell Signal, 22: 1645-54.

[55] Hayes JD, Ashford ML (2012). Nrf2 Orchestrates Fuel Partitioning for Cell Proliferation. Cell Metab, 16: 13941.

[56] Kwak MK, Itoh K, Yamamoto M, Sutter TR, Kensler TW (2001). Role of transcription factor Nrf2 in the induction of hepatic phase 2 and antioxidative enzymes in vivo by the cancer chemoprotective agent, 3H-1, 2dimethiole-3-thione. Mol Med, 7: 135-45.

[57] Hayashi A, Suzuki H, Itoh K, Yamamoto M, Sugiyama $\mathrm{Y}$ (2003). Transcription factor Nrf2 is required for the constitutive and inducible expression of multidrug resistance-associated protein1 in mouse embryo fibroblasts. Biochem Biophys Res Commun, 310: 824-9.

[58] Guo Y, Yu S, Zhang C, Kong AN (2015). Epigenetic regulation of Keap1-Nrf2 signaling. Free Radic Biol Med, 88: 337-49.

[59] Bellezza I, Mierla A L, Minelli A (2010). Nrf2 and NF$\kappa \mathrm{B}$ and their concerted modulation in cancer pathogenesis and progression. Cancers, 2: 483-97.
[60] Bellezza I, Grottelli S, Gatticchi L, Mierla AL, Minelli A (2014). $\alpha$-Tocopheryl succinate pre-treatment attenuates quinone toxicity in prostate cancer PC3 cells. Gene, 539: 1-7.

[61] Sandberg M, Patil J, D'angelo B, Weber SG, Mallard C (2014). NRF2-regulation in brain health and disease: implication of cerebral inflammation. Neuropharmacology, 79: 298-306.

[62] Bellezza I, Tucci A, Galli F, Grottelli S, Mierla AL, Pilolli F, et al. (2012). Inhibition of NF- $\kappa B$ nuclear translocation via HO-1 activation underlies $\alpha$-tocopheryl succinate toxicity. J Nutr Biochem 23: 1583-91.

[63] Cuadrado A, Martín-Moldes Z, Ye J, Lastres-Becker I. (2014). Transcription factors NRF2 and NF- $\mathrm{BB}$ are coordinated effectors of the Rho family, GTP-binding protein RAC1 during inflammation. J Biol Chem, 289: 15244-58.

[64] Magesh S, Chen Y, Hu L (2012). Small molecule modulators of Keap1-Nrf2-ARE pathway as potential preventive and therapeutic agents. Med Res Rev, 32: 687-72.

[65] Kim J, Cha Y N, Surh YJ (2010). A protective role of nuclear factor-erythroid 2-related factor-2 (Nrf2) in inflammatory disorders. Mutat Res, 690: 12-23.

[66] Calkins MJ, Johnson DA, Townsend JA, Vargas MR, Dowell JA, Williamson TP, et al. (2009). The Nrf2/ARE pathway as a potential therapeutic target in neurodegenerative disease. Antioxid Redox Signal, 11: 497-508.

[67] Williamson TP, Johnson DA, Johnson JA (2012). Activation of the Nrf2-ARE pathway by siRNA knockdown of Keap1 reduces oxidative stress and provides partial protection from MPTP-mediated neurotoxicity. Neurotoxicology, 33: 272-9.

[68] Mota SI, Costa RO, Ferreira IL, Santana I, Caldeira GL, Padovano C, et al. (2015). Oxidative stress involving changes in Nrf2 and ER stress in early stages of Alzheimer's disease. Biochim Biophys Acta, 1852 142841.

[69] Jin XF, Wang S, Shen M, Wen X, Han XR, Wu JC, et al. (2017). Effects of rehabilitation training on apoptosis of nerve cells and the recovery of neural and motor functions in rats with ischemic stroke through the PI3K/Akt and Nrf2/ARE signaling pathways. Brain Res Bull, 134: 236-45.

[70] Ruiz S, Pergola PE, Zager RA, Vaziri ND (2013). Targeting the transcription factor Nrf2 to ameliorate oxidative stress and inflammation in chronic kidney disease. Kidney Int 83: 1029-41.

[71] Aboonabi A, Singh I (2015). Chemopreventive role of anthocyanins in atherosclerosis via activation of Nrf2ARE as an indicator and modulator of redox. Biomed Pharmacother, 72: 30-6.

[72] Chartoumpekis DV, W Kensler TW (2013). New player on an old field; the keap1/Nrf2 pathway as a target for treatment of type 2 diabetes and metabolic syndrome. Curr Diabetes Rev 9: 137-45.

[73] Li J, Ichikawa T, Janicki JS, Cui T (2009). Targeting the Nrf2 pathway against cardiovascular disease. Expert Opin Ther Targets, 13: 785-94. 
[74] Su X, Li T, Liu Z, Huang Q, Liao K, Ren R, et al. (2018). Licochalcone A activates Keap1-Nrf2 signaling to suppress arthritis via phosphorylation of p62 at serine 349. Free Radic Biol Med, 115: 471-83.

[75] Powers SK, Jackson MJ (2008). Exercise-induced oxidative stress: cellular mechanisms and impact on muscle force production, Physiol Rev, 88: 1243-1276.

[76] Merry TL, Ristow M (2016). Nuclear factor erythroidderived 2-like 2 (NFE2L2, Nrf2) mediates exerciseinduced mitochondrial biogenesis and the anti-oxidant response in mice. J Physiol, 594: 5195-207.

[77] Duan F, Guo Y, Li J, Yuan K (2017). Antifatigue Effect of Luteolin-6-C-Neohesperidoside on Oxidative Stress Injury Induced by Forced Swimming of Rats through Modulation of Nrf2/ARE Signaling Pathways. Oxid Med Cell Longev, 2017:3159358.

[78] Shanmugam G, Narasimhan M, Conley RL, Sairam T, Kumar A, Mason RP, et al. (2017). Chronic endurance exercise impairs cardiac structure and function in middle-aged mice with impaired Nrf2 signaling. Front Physiol, 2017, 8: 268.

[79] Uruno A, Yagishita Y, Katsuoka F, Kitajima Y, Nunomiya A, Nagatomi R, et al. (2016). Nrf2-mediated regulation of skeletal muscle glycogen metabolism. Mol Cell Biol, 36:1655-72.

[80] Done AJ, Gage MJ, Nieto NC, Traustadóttir T (2016) Exercise-induced Nrf2-signaling is impaired in aging. Free Radic Biol Med, 96: 130-8.

[81] Magbanua MJM, Richman E L, Sosa EV, Jones LW, Simko J, Shinohara K, et al. (2014). Physical activity and prostate gene expression in men with low-risk prostate cancer[J]. Cancer Causes Control, 25: 515-23.

[82] Perry CG, Lally J, Holloway GP, Heigenhauser GJ, Bonen A, Spriet LL (2010). Repeated transient mRNA bursts precede increases in transcriptional and mitochondrial proteins during training in human skeletal muscle. J Physiol, 588: 4795-810.

[83] Gomes FC, Chuffa LG, Scarano R, Pinheiro PF, Fávaro WJ, Domeniconi RF (2016). Nandrolone decanoate and resistance exercise training favor the occurrence of lesions and activate the inflammatory response in the ventral prostate. Andrology, 4: 473-80.

[84] Minelli A, Bellezza I, Conte C, Culig Z (2009). Oxidative stress-related aging: A role for prostate cancer? Biochim Biophys Acta, 1795: 83-91.

[85] Upadhyay S, Dixit M (2015). Role of polyphenols and other phytochemicals on molecular signaling. Oxid Med Cell Longev, 2015: 504253.

[86] Csiszar A, Gautam T, Sosnowska D, Tarantini S, Banki E, Tucsek Z, et al. (2014). Caloric restriction confers persistent anti-oxidative, pro-angiogenic, and antiinflammatory effects and promotes anti-aging miRNA expression profile in cerebromicrovascular endothelial cells of aged rats. Am J Physiol Heart Circ Physiol, 307: H292-306.

[87] Oh S, Komine S, Warabi E, Akiyama K, Ishii A, Ishige $\mathrm{K}$, et al. (2017). Nuclear factor (erythroid derived 2)-like 2 activation increases exercise endurance capacity via redox modulation in skeletal muscles. Sci Rep, 7: 12902.
[88] Riuzzi F, Sorci G, Sagheddu R, Donato R (2012). HMGB1-RAGE regulates muscle satellite cell homeostasis through p38-MAPK-and myogenindependent repression of Pax7 transcription. J Cell Sci, 125: 1440-54.

[89] Lim S, Shin JY, Jo A, Jyothi KR, Nguyen MN, Choi TG, et al. (2013). Carbonyl reductase 1 is an essential regulator of skeletal muscle differentiation and regeneration. Int J Biochem Cell Biol, 45: 1784-93.

[90] Horn A, Van der Meulen JH, Defour A, Hogarth M, Sreetama SC1, Reed A, et al. (2017). Mitochondrial redox signaling enables repair of injured skeletal muscle cells. Sci Signal, 10.

[91] Linker R A, Lee D H, Ryan S, van Dam AM, Conrad R, Bista P, et al. (2011). Fumaric acid esters exert neuroprotective effects in neuroinflammation via activation of the Nrf2 antioxidant pathway. Brain, 134: 678-92.

[92] Sack MN, Fyhrquist FY, Saijonmaa OJ, Fuster V, Kovacic JC (2017). Basic Biology of Oxidative Stress and the Cardiovascular System: Part 1 of a 3-Part Series. J Am Coll Cardiol, 70: 196-211.

[93] Bai Y, Wang X, Zhao S, Ma C, Cui J, Zheng Y (2015). Sulforaphane protects against cardiovascular disease via Nrf2 activation. Oxid Med Cell Longev. 2015; doi: $10.1155 / 2015 / 407580$.

[94] Deng S, Wang X, Essandoh K (2017). Tsg101 Regulates the P62-Keap1-Nrf2 Axis in Cardiomyocytes to Protect Against Cardiac Ischemia/Reperfusion Injury. Circulation, 136: A19367

[95] Cominacini L, Mozzini C, Garbin U, Pasini A, Stranieri C, Solani E, et al. (2015). Endoplasmic reticulum stress and Nrf2 signaling in cardiovascular diseases. Free Radic Biol Med, 88: 233-42.

[96] Smith RE, Tran K, Smith CC, McDonald M, Shejwalkar P, Hara K (2016). The role of the Nrf2/ARE antioxidant system in preventing cardiovascular diseases. Diseases, 4(4). pii: E34

[97] Yan SH, Zhao NW, Geng ZR, Shen JY, Liu FM, Yan D, et al. (2018). Modulations of Keap1-Nrf2 signaling axis by TIIA ameliorated the oxidative stress-induced myocardial apoptosis. Free Radic Biol Med, 115: 191201.

[98] Yang YC, Lii C K, Lin A H, Yeh YW, Yao HT, Li CC, et al. (2011). Induction of glutathione synthesis and heme oxygenase 1 by the flavonoids butein and phloretin is mediated through the ERK/Nrf2 pathway and protects against oxidative stress. Free Radic Biol Med, 51: 207381.

[99] Kobayashi M, Yamamoto M (2005). Molecular mechanisms activating the Nrf2-Keap1 pathway of antioxidant gene regulation. Antioxid Redox Signal, 7: 385-94.

[100] Smyrnias I, Zhang X, Zhang M, Murray TV, Brandes RP, Schröder K, et al. (2015). Nicotinamide adenine dinucleotide phosphate oxidase-4-dependent upregulation of nuclear factor erythroid-derived 2-like 2 protects the heart during chronic pressure overload. Hypertension 65: 547-53. 
[101] Maddux BA, See W, Lawrence JC Jr, Goldfine AL, Goldfine ID, Evans JL (2001). Protection against oxidative stress-induced insulin resistance in rat L6 muscle cells by micromolar concentrations of alphalipoic acid. Diabetes; 50:404-10.

[102] Matsuoka T, Kajimoto Y, Watada H, Kaneto H, Kishimoto M, Umayahara Y, et al. (1997). Glycationdependent, reactive oxygen species-mediated suppression of the insulin gene promoter activity in HIT cells. J Clin Invest, 99:144-50.

[103] Uruno A, Yagishita Y, Yamamoto M (2015). The Keap1-Nrf2 system and diabetes mellitus[J]. Arch Biochem Biophys, 566: 76-84.

[104] Sakuraba H, Mizukami H, Yagihashi N, Wada R, Hanyu C, Yagihashi S (2002). Reduced beta-cell mass and expression of oxidative stress-related DNA damage in the islet of Japanese Type II diabetic patients. Diabetologia, 45: 85-96.

[105] Sasaki M, Fujimoto S, Sato Y, Nishi Y, Mukai E, Yamano G, et al. (2013). Reduction of reactive oxygen species ameliorates metabolism-secretion coupling in islets of diabetic GK rats by suppressing lactate overproduction. Diabetes, 62: 1996-2003.

[106] Kaneto H, Kajimoto Y, Miyagawa J, Matsuoka T, Fujitani Y, Umayahara Y, et al. (1999). Beneficial effects of antioxidants in diabetes: possible protection of pancreatic beta-cells against glucose toxicity. Diabetes, 48: 2398-406.

[107] Hayes JD, Dinkova-Kostova AT (2014). The Nrf2 regulatory network provides an interface between redox and intermediary metabolism. Trends Biochem Sci, 39: 199-218.

[108] Yang B, Fu J, Zheng H, Xue P, Yarborough K, Woods $C$, et al. (2012). Deficiency in the nuclear factor E2related factor 2 renders pancreatic $\beta$-cells vulnerable to arsenic-induced cell damage. Toxicol Appl Pharmacol, 264: 315-23.

[109] Song MY, Kim EK, Moon WS, Park JW, Kim HJ, So HS, et al. (2009). Sulforaphane protects against cytokine-and streptozotocin-induced $\beta$-cell damage by suppressing the NF- $\kappa \mathrm{B}$ pathway. Toxicol Appl Pharmacol, 235: 57-67.

[110] Li W, Wu W, Song H, Wang F, Li H, Chen L, et al. (2014). Targeting Nrf2 by dihydro-CDDO-trifluoroethyl amide enhances autophagic clearance and viability of $\beta$ cells in a setting of oxidative stress. FEBS letters, 588: 2115-24.

[111] Lee S, Hur E, Ryoo I, Jung K, Kwak J, Kwak M (2012). Involvement of the Nrf2-proteasome pathway in the endoplasmic reticulum stress response in pancreatic $\beta$ cells. Toxicol Appl Pharmacol, 264: 431-8.

[112] Bae EJ, Yang YM, Kim JW, Kim SG (2007). Identification of a novel class of dithiolethiones that prevent hepatic insulin resistance via the adenosine monophosphate-activated protein kinase-p70 ribosomal S6 kinase-1 pathway. Hepatology, 46: 730-9.

[113] Meher AK, Sharma PR, Lira V A, Yamamoto M, Kensler TW, Yan Z, et al. (2012). Nrf2 deficiency in myeloid cells is not sufficient to protect mice from high- fat diet-induced adipose tissue inflammation and insulin resistance. Free Radic Biol Med, 52: 1708-15.

[114] Xue P, Hou Y, Chen Y, Yang B, Fu J, Zheng H, et al. (2013). Adipose deficiency of Nrf2 in ob/ob mice results in severe metabolic syndrome. Diabetes, 62: 845-54.

[115] Yoh K, Hirayama A, Ishizaki K, Yamada A, Takeuchi M, Yamagishi S, et al. (2008). Hyperglycemia induces oxidative and nitrosative stress and increases renal functional impairment in Nrf2-deficient mice. Genes Cells, 13: 1159-70.

[116] Xu Z, Wei Y, Gong J, Cho H, Park JK, Sung ER, et al. (2014). NRF2 plays a protective role in diabetic retinopathy in mice. Diabetologia, 57: 204-13.

[117] Tan Y, Ichikawa T, Li J, Si Q, Yang H, Chen X, et al. (2011). Diabetic downregulation of Nrf2 activity via ERK contributes to oxidative stress-induced insulin resistance in cardiac cells in vitro and in vivo. Diabetes, 60: 625-33.

[118] Taguchi K, Yamamoto M (2017). The KEAP1-NRF2 system in cancer. Frontiers in oncology, 7: 85.

[119] Lu K, Alcivar A L, Ma J, Foo TK, Zywea S1, Mahdi A, et al. (2017). NRF2 Induction Supporting Breast Cancer Cell Survival Is Enabled by Oxidative Stress-Induced DPP3-KEAP1 Interaction. Cancer Res, 77: 2881-92.

[120] Tsuchida K, Tsujita T, Hayashi M, Ojima A, KelekuLukwete N, Katsuoka F, et al. (2017). Halofuginone enhances the chemo-sensitivity of cancer cells by suppressing NRF2 accumulation. Free Radic Biol Med. 103: 236-47.

[121] Milkovic L, Zarkovic N, Saso L (2017). Controversy about pharmacological modulation of Nrf2 for cancer therapy. Redox biology, 12: 727-32.

[122] Deshmukh P, Unni S, Krishnappa G, Padmanabhan B (2017). The Keap1-Nrf2 pathway: promising therapeutic target to counteract ROS-mediated damage in cancers and neurodegenerative diseases. Biophys Rev, 9: 41-56.

[123] Jeong Y, Hoang NT, Lovejoy A, Stehr H, Newman AM, Gentles AJ, et al. (2017). Role of KEAP1/NRF2 and TP53 mutations in lung squamous cell carcinoma development and radiation resistance. Cancer Discov, 7: 86-101.

[124] Lau A, Villeneuve NF, Sun Z, Wong PK, Zhang DD. (2008). Dual roles of Nrf2 in cancer. Pharmacol Res, 58:262-70.

[125] Ooi A, Dykema K, Ansari A, Petillo D, Snider J, Kahnoski R, et al. (2013). CUL3 and Nrf2 mutations confer an Nrf2 activation phenotype in a sporadic form of papillary renal cell carcinoma. Cancer Res, 73:204451.

[126] Rajabi H, Tagde A, Alam M, Bouillez A, Pitroda S, Suzuki Y, et al. (2016). DNA methylation by DNMT1 and DNMT3b methyltransferases is driven by the MUC1-C oncoprotein in human carcinoma cells. Oncogene, 35: 6439-45.

[127] Tagde A, Rajabi H, Stroopinsky D, Gali R, Alam M, Bouillez A, et al. (2016). MUC1-C induces DNA methyltransferase 1 and represses tumor suppressor genes in acute myeloid leukemia. Oncotarget, 7:3897487. 
[128] Faraonio R, Vergara P, DiMarzo D, Pierantoni MG, NapolitanoM, Russo T, et al. (2006). p53 suppresses the Nrf2-dependent transcription of antioxidant response genes. J Biol Chem, 281:39776-84.

[129] DeNicola GM, Karreth FA, Humpton TJ, Gopinathan A, Wei C, Frese K, et al. (2011). Oncogene-induced Nrf2 transcription promotes ROS detoxification and tumorigenesis. Nature, 475:106-9.

[130] Adam J, Hatipoglu E, O'Flaherty L, Ternette N, Sahgal $\mathrm{N}$, Lockstone $\mathrm{H}$, et al. (2011). Renal cyst formation in Fh1-deficient mice is independent of the Hif/Phd pathway: roles for fumarate in Keap1 succination and Nrf2 signaling. Cancer Cell, 20:524-37.

[131] Tanaka A, Hamada N, Fujita Y, Itoh T, Nozawa Y, Iinuma M, et al. (2010). A novel kavalactone derivative protects against $\mathrm{H} 2 \mathrm{O} 2$-induced $\mathrm{PC} 12$ cell death via Nrf2/ARE activation. Bioorg Med Chem, 18:3133-9.

[132] Tusi SK, Ansari N, Amini M, Amirabad AD, Shafiee A, Khodagholi F, et al. (2010). Attenuation of NF-kappaB and activation of Nrf2 signaling by 1,2,4-triazine derivatives, protects neuronlike PC12 cells against apoptosis. Apoptosis, 15:738-51.

[133] Kerr F, Sofola-Adesakin O, Ivanov DK, Gatliff J, Gomez Perez-Nievas B, Bertrand HC, et al. (2017). Direct Keap1-Nrf2 disruption as a potential therapeutic target for Alzheimer's disease. PLoS genetics, 13: e1006593.

[134] Branca C, Ferreira E, Nguyen TV, Doyle K, Caccamo A, Oddo S (2017). Genetic reduction of Nrf2 exacerbates cognitive deficits in a mouse model of Alzheimer's disease. Hum Mol Genet, 26: 4823-35.

[135] Lipton SA, Rezaie T, Nutter A, Lopez KM, Parker J, Kosaka K, et al. (2016). Therapeutic advantage of proelectrophilic drugs to activate the Nrf2/ARE pathway in Alzheimer's disease models. Cell Death Dis, 7: e2499.

[136] Kanninen K, White AR, Koistinaho J, Malm T (2011). Targeting glycogen synthase kinase- $3 \beta$ for therapeutic benefit against oxidative stress in Alzheimer's disease: involvement of the Nrf2-ARE Pathway. Int J Alzheimer Dis, 2011: 98508.

[137] Ramsey CP, Glass CA, Montgomery MB, Lindl KA, Ritson GP, Chia LA, et al. (2007). Expression of Nrf2 in neurodegenerative diseases. J Neuropathol Exp Neurol, 66:75-85.

[138] Pan PK, Qiao LY, Wen XN (2016). Safranal prevents rotenone-induced oxidative stress and apoptosis in an in vitro model of Parkinson's disease through regulating Keap1/Nrf2 signaling pathway. Cell Mol Biol, 62: 11-7.

[139] Lastres-Becker I (2017). Role of the Transcription Factor Nrf2 in Parkinson's Disease: New Insights. J Alzheimers Dis Parkinsonism, 2017, DOI: 10.4172/21610460.1000340

[140] Ran C, Wirdefeldt K, Brodin L, Ramezani M, Westerlund M, Xiang F, et al. (2017). Genetic Variations and mRNA Expression of NRF2 in Parkinson's Disease. Parkinsons Dis, 2017; doi: 10.1155/2017/4020198.

[141] Lastres-Becker I, García-Yagüe A J, Scannevin RH, Casarejos MJ, Kügler S, Rábano A, et al. (2016). Repurposing the NRF2 activator dimethyl fumarate as therapy against synucleinopathy in Parkinson's disease. Antioxid Redox Signal, 25: 61-77.
[142] Zhang R, Xu M, Wang Y, Xie F, Zhang 1, Qin X (2017). Nrf2-a promising therapeutic target for defensing against oxidative stress in stroke. Mol Neurobiol, 54: 6006-17.

[143] Jiang S, Deng C, Lv J, Fan C, Hu W, Di S, et al. (2017). Nrf2 weaves an elaborate network of neuroprotection against stroke. Mol Neurobiol, 54: 1440-55.

[144] Meng H, Guo J, Wang H, Yan P, Niu X, Zhang J (2014). Erythropoietin activates Keap1-Nrf2/ARE pathway in rat brain after ischemia. Int J Neurosci, 124: 362-8.

[145] Wu S, Yue Y, Peng A, Zhang L, Xiang J, Cao X, et al. (2016). Myricetin ameliorates brain injury and neurological deficits via Nrf2 activation after experimental stroke in middle-aged rats. Food Funct, 7: 2624-34.

[146] Wang Y, Huang Y, Xu Y, Ruan W, Wang H, Zhang Y, et al. (2018). A dual AMPK/Nrf2 activator reduces brain inflammation after stroke by enhancing microglia M2 polarization. Antioxid Redox Signal 28: 141-63.

[147] Shah ZA, Li RC, Thimmulappa RK, Kensler TW, Yamamoto M, Biswal S, et al. (2007). Role of reactive oxygen species in modulation ofNrf 2 following ischemic reperfusion injury. Neuroscience, 147:53-9.

[148] Shih AY, Li P, Murphy TH (2005). A small-moleculeinducible Nrf2-mediated antioxidant response provides effective prophylaxis against cerebral ischemia in vivo. $\mathbf{J}$ Neurosci, 25:10321-35.

[149] Wang B, Zhu X, Kim Y, Li J, Huang S, Saleem S, et al. (2012). Histone deacetylase inhibition activates transcription factor Nrf2 and protects against cerebral ischemic damage. Free Radic Biol Med, 52: 928-36.

[150] Li L, Zhang X, Cui L, Wang L, Liu H, Ji H, et al. (2013). Ursolic acid promotes the neuroprotection by activating Nrf2 pathway after cerebral ischemia in mice. Brain Res, 1497:32-9.

[151] Calkins MJ, Johnson DA, Townsend J A, Vargas MR, Dowell JA, Williamson TP, et al. (2009). The Nrf2/ARE pathway as a potential therapeutic target in neurodegenerative disease. Antioxid Redox Signal, 11: 497-508.

[152] Wu K C, Liu J, Klaassen CD (2012). Role of Nrf2 in preventing ethanol-induced oxidative stress and lipid accumulation. Toxicol Appl Pharmacol, 262: 321-9.

[153] Chi X, Zhang R, Shen N, Jin Y, Alina A, Yang S, et al. (2015). Sulforaphane reduces apoptosis and oncosis along with protecting liver injury-induced ischemic reperfusion by activating the Nrf2/ARE pathway. Hepatol Int, 9: 321-9.

[154] Shen Z, Wang Y, Su Z, Kou R, Xie K, Song F, et al. (2018). Activation of p62-keap1-Nrf2 antioxidant pathway in the early stage of acetaminophen-induced acute liver injury in mice. Chem Biol Interact, 282:22-8

[155] Posten W, Wrone DA, Dover JS, Arndt KA, Silapunt S, Alam M (2005). Low-level laser therapy for wound healing: mechanism and efficacy. Dermatol Surg, 31:334-40.

[156] Frigo L, Luppi JSS, Favero GM, Maria DA, Penna SC, Bjordal JM, et al. (2009). The effect of low-level laser irradiation (In-Ga-Al-AsP-660 $\mathrm{nm}$ ) on melanoma in vitro and in vivo. BMC cancer, 9: 404. 
[157] Mackiewicz-Milewska M, Grześk E, Kroszczyński AC, Cisowska-Adamiak M, Mackiewicz-Nartowicz H, Baran L, et al. (2018). The influence of low level laser irradiation on vascular reactivity. Adv Med Sci, 63: 647.

[158] Xuan W, Agrawal T, Huang L, Gupta GK, Hamblin MR (2015). Low-level laser therapy for traumatic brain injury in mice increases brain derived neurotrophic factor (BDNF) and synaptogenesis. J Biophotonics, 8: 502-11.

[159] Leal-Junior ECP, Vanin A A, Miranda EF, de Carvalho Pde T, Dal Corso S, Bjordal JM (2015). Effect of phototherapy (low-level laser therapy and light-emitting diode therapy) on exercise performance and markers of exercise recovery: a systematic review with metaanalysis. Lasers Med Sci, 30: 925-39.

[160] Tuby H, Maltz L, Oron U (2007). Low-level laser irradiation (LLLI) promotes proliferation of mesenchymal and cardiac stem cells in culture. Lasers Surg Med, 39: 373-8.

[161] Albertini R, Villaverde AB, Aimbire F, Salgado MA, Bjordal JM, Alves LP, et al. (2007). Anti-inflammatory effects of low-level laser therapy (LLLT) with two different red wavelengths (660 $\mathrm{nm}$ and $684 \mathrm{~nm})$ in carrageenan-induced rat paw edema. J Photochem Photobiol B 89: 50-5.

[162] De Scheerder IK, Wang K, Zhou XR, Szilard M, Verbeken E, Ping QB, et al. (2000). Intravascular lowpower red laser light as an adjunct to coronary stent implantation: Initial clinical experience. Catheter Cardiovasc Interv, 49: 468-71.

[163] Farivar S, Malekshahabi T, Shiari R (2014). Biological effects of low level laser therapy. J Lasers Med Sci, 5: 58-62.

[164] Macedo AB, Moraes L HR, Mizobuti DS, Fogaça AR, Moraes Fdos S, Hermes Tde A, et al. (2015). Low-level laser therapy (LLLT) in dystrophin-deficient muscle cells: effects on regeneration capacity, inflammation response and oxidative stress. PloS one, 10: e0128567.

[165] Lubart R, Eichler M, Lavi R, Friedman H, Shainberg A (2015). Low-energy laser irradiation promotes cellular redox activity. Photomed Laser Surg, 23(1):3-9.

[166] Souza NHC, Marcondes PT, Albertini R, MesquitaFerrari RA, Fernandes KP, Aimbire F (2014). Low-level laser therapy suppresses the oxidative stress-induced glucocorticoids resistance in U937 cells: relevance to cytokine secretion and histone deacetylase in alveolar macrophages. J Photochem Photobiol B, 130: 327-36.

[167] Ahmed OM, Mohamed T, Moustafa H, Hamdy H, Ahmed RR, Aboud E (2018). Quercetin and low level laser therapy promote wound healing process in diabetic rats via structural reorganization and modulatory effects on inflammation and oxidative stress. Biomed Pharmacother, 101: 58-73.

[168] Silveira PC, Silva LA, Freitas TP, Latini A, Pinho RA (2011). Effects of low-power laser irradiation (LPLI) at different wavelengths and doses on oxidative stress and fibrogenesis parameters in an animal model of wound healing. Lasers Med Sci, 26: 125-31.
[169] Assis L, Moretti AI, Abrahão TB, Cury V, Souza HP, Hamblin MR, et al. (2012). Low-level laser therapy (808 $\mathrm{nm}$ ) reduces inflammatory response and oxidative stress in rat tibialis anterior muscle after cryolesion. Lasers Surg Med, 44: 726-35.

[170] Lima FM, Albertini R, Dantas Y, Maia-Filho AL, Santana Cde L, Castro-Faria-Neto HC, et al. (2013). Low-Level Laser Therapy Restores the Oxidative Stress Balance in Acute Lung Injury Induced by Gut Ischemia and Reperfusion. Photochem Photobiol, 89: 179-88.

[171] De Marchi T, Junior EC, Bortoli C, Tomazoni SS, Lopes-Martins RA, Salvador M (2012). Low-level laser therapy (LLLT) in human progressive-intensity running: effects on exercise performance, skeletal muscle status, and oxidative stress. Lasers Med Sci, 27: 231-6.

[172] Jankowski M, Gawrych M, Adamska U, Ciescinski J, Serafin Z, Czajkowski R (2017). Low-level laser therapy (LLLT) does not reduce subcutaneous adipose tissue by local adipocyte injury but rather by modulation of systemic lipid metabolism. Lasers Med Sci, 32: 475-9. 